\title{
The application of External and Mixed Idea Management Systems during COVID19 time
}

\author{
Elina Mikelsone ${ }^{1,}$, Tatjana Volkova $^{1}$, Aivars Spilbergs ${ }^{1}$, and Elita Liela ${ }^{1}$ \\ ${ }^{1}$ BA School of Business and Finance, Faculty of Business Administration, Kr.Valdemara Street 161, \\ LV-1013, Riga, Latvia
}

\begin{abstract}
Research background: Authors have explored that there are different idea management system application types that could be used both locally and globally. But there is the question - how organizations can benefit from these systems during COVID19?

Purpose of the article: The article aims to clarify how external and mixed web-based idea management systems could be used during COVID19 time for distance idea generation sessions, as well to solve complex problems with different idea generation sources and evaluators

Methods: Literature review (data collection: systematically data collection from scientific data bases; data analysis: content analysis). Survey of $n>400$ enterprises with web-based IMS experience (data collection: survey; data analysis: statistics). Case studies (data collection: web-based idea management system creator secondary data; data analysis: content analysis). Findings \& Value added: External and mixed web-based idea management systems are great tools during COVID19 time for distance idea generation sessions as well to solve serious problems with different idea generation sources and evaluators. These tools could be used by private, public organizations, as well by higher education institutions and research institutions as an innovation actor under the Triple Helix Model. By involving all these organizations in the idea management process the innovation potential is increasing.
\end{abstract}

Keywords: Idea Management Systems; Web-based Idea Management Systems; Globalization; Open Innovation; COVID19

JEL Classification: L86; D89; D79; M15

\footnotetext{
*Corresponding author: elina.mikelsone@ba.lv
} 


\section{Introduction}

According to Alonso et al. [1] investigating businesses capacity to adapt to the COVID-19 pandemic, or the extent to which they undertake changes and adjustments in this new regime merits consideration of associated theoretical underpinnings and concepts are required.

The authors believe that in the circumstances under pandemic will make firms rethink their approach to managing innovation activities based on open innovation approach. Such is the case of the Web-based ideas management systems, applying which firms' can deliver solutions in a fast changing environment dealing with current extreme events.

There are closed, open and mixed web idea management-based systems that helps for organisations systematically manage ideas by several idea generation and evaluation processes.

From the authors point of view open and mixed web-based idea management systems allow to deliver effective solutions by applying open innovations, inviting stakeholders to be co-creators of these solutions.

In line with the scholarly work that has followed the original open-innovation definition [2-7] define open innovation as "a distributed innovation process based on purposively managed knowledge flows across organizational boundaries, using pecuniary and nonpecuniary mechanisms in line with the organization's business model." [8]

Open innovation based on open and mixed web-based idea management systems during ideation stage of innovative activities could be applied in any activity of organization, e.g. looking for partnership innovations [9], customer relationships innovation [10-11], value innovations, supply chain innovations [12-14], customer experience management innovations [15], sustainable human resources development [16], [17], etc.

During COVID -19 times the application of open innovation systems allows to deliver innovations faster to cope with the challenges firms are facing by outsourcing ideas from outside alongside with generation of ideas inside the firm. As it was pointed out by Donthu and Gustafsson [18] one of the consequences of the COVID 19 related lockdowns is the extreme increase in the usage of Internet and social media. This trend has to be turned into opportunity by wider application of web-based idea management systems by organizations.

Application of open innovations also for web-based idea management requires changing organizational culture of firms. There is an untapped innovation potential in firms towards delivering not only product or service innovations, but also towards value delivery channels innovations, customer relationship management innovations, customer experience management innovations, etc. The involvement of Quadruple Helix model actors such as business, public administration, academia and research institutions and society would lead to higher number of ideas and higher quality ideas generated through web- based ideas management. Research background: Authors have explored that there are different idea management system application types that could be used both locally and globally. But there is the question - how organizations can benefit from these systems during COVID19?

Purpose of the article: The article aims to clarify how external and mixed web-based idea management systems could be used during COVID19 time for distance idea generation sessions, as well to solve complex problems with different idea generation sources and evaluators

Methods: Literature review (data collection: systematically data collection from scientific data bases; data analysis: content analysis). Survey of $n>400$ enterprises with web-based IMS experience (data collection: survey; data analysis: statistics). Case studies (data collection: web-based idea management system creator secondary data; data analysis: content analysis). 


\section{Research methodology}

The aim of research is to clarify how external and mixed web-based idea management systems (IMS) could be used during COVID19 time for distance idea generation sessions, as well to solve complex problems with different idea generation sources and evaluators. The research methods applied are literature review (data collection: systematically data collection from scientific databases; data analysis: content analysis). Survey of $n>400$ enterprises with web-based IMS experience (data collection: survey; data analysis: statistics). Case studies (data collection: web-based idea management system creator secondary data; data analysis: content analysis).

\section{Results}

\subsection{Basic data characteristics - idea quantity}

Respondents frequency distribution based on survey data is shown in Figure 1.

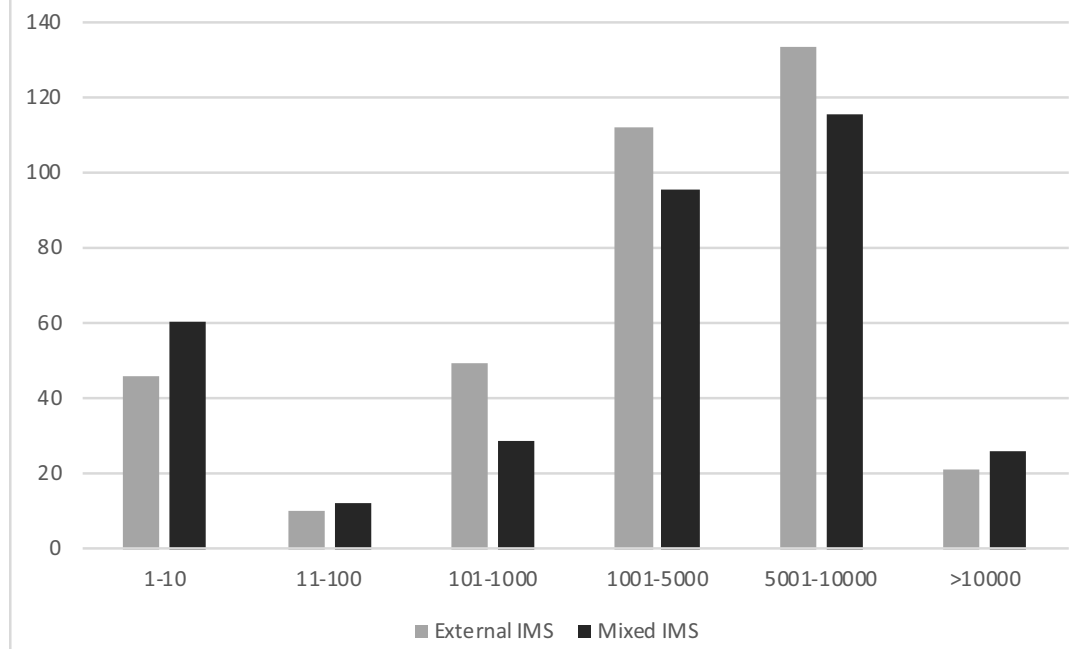

Fig. 1. Respondents frequency distribution for idea quantity based on sample data Source: created by author's

The further detailed analysis consists of the arithmetic mean of the group, standard deviation, modal and medial class (group), coefficient of variation. Arithmetic mean of grouped data is calculated as follows:

$$
\bar{x}=\frac{\sum_{1}^{K} f_{i} \cdot m_{i}}{n}
$$

where: $m_{i} \quad i$ th class (group) midpoint,

$$
\begin{array}{ll}
f_{i} & \text { frequency of the } i \text { th class (interval), } \\
n & \text { sample size, } n=\sum_{1}^{K} f_{i} .
\end{array}
$$

The standard deviation of grouped data is calculated as follows:

$$
s=\sqrt{\frac{s^{2}}{n} \cdot\left(1-\frac{n}{N}\right)}
$$

where: $s^{2}=\frac{1}{n-1} \cdot \sum_{1}^{K} f_{i} \cdot\left(m_{i}-\bar{x}\right)^{2}$

$m_{i} \quad i$ th class (group) midpoint. 
The median $(M e)$ of grouped data is calculated as follows:

$$
M e=x_{M e, l}+\frac{\left(\frac{\sum f}{2}-c f_{M e-1}\right) \cdot \Delta_{M e}}{f_{M e}}
$$

where: $x_{M e, l} \quad$ lower class boundary of the interval containing the median,

$c f_{M e-1}$ cumulative frequency of the interval before the median interval,

$f_{M e} \quad$ frequency of the median interval,

$\Delta_{M e} \quad$ the median interval width.

Medial interval is interval for which accumulated frequencies first time is equal or larger than half of the sample size.

Coefficient of variation $(\mathrm{CV})$ is calculated as follows:

$$
C V=\frac{s}{x} \cdot 100 \%
$$

Point estimates for idea quantity were aggregated and are provided in Table 1.

Table 1. Point estimates for idea quantity

\begin{tabular}{|c|c|c|c|c|c|}
\hline IMS type & $\boldsymbol{n}$ & Mean & Median & $\boldsymbol{s}$ & $\boldsymbol{C V}$ \\
\hline External IMS & 371 & 4377,1 & 3875,5 & 3543,5 & $81 \%$ \\
\hline Mixed IMS & 337 & 4420,1 & 3842,6 & 3771,4 & $85 \%$ \\
\hline
\end{tabular}

Source: created by author's

As shown in Table 1, the medians for both IMS types are less than the means of the generated ideas. These differences indicate some asymmetry in the distribution of respondents - more often a smaller number of ideas are generated, but less often - a large number of ideas. As frequency distributions are skewed mean values does not give a good idea of a typical value that can be expected in case of using these types of IMS. The calculated coefficients of variation indicate that at approximately equal median values, using mixed IMS, slightly larger volatilities in the number of generated ideas must be taken into account.

\subsection{Hypothesis testing - idea quantity}

Basic data set analysis showed that it is possible to test the hypothesis on the gathered data. That is the reason why further in this paper the authors conduct significance tests for population mean number of ideas created (idea quantity). A respondent's frequency distribution shows the main trend that will be tested: mixed IMS provides higher idea quantity than external IMS. Hypothesis 1 statement: Mixed IMS provide higher idea quantity than external.

$$
H_{0}: \bar{x}_{M C}-\bar{x}_{E C} \leq 0 \text { and } H_{A}: \bar{x}_{M C}-\bar{x}_{E C}>0
$$

As sample sizes un standard deviations differs, the test statistics are calculated as follows, [19]:

$$
t=\frac{\bar{x}_{i}-\bar{x}_{j}}{\sqrt{\frac{s_{i}^{2}}{n_{i}}+\frac{s_{j}^{2}}{n_{j}}}}
$$

where: $\bar{x}_{i}$ and $\bar{x}_{j}$ $s_{i}^{2}$ and $s_{j}^{2}$ variables, $n_{i}$ and $n_{j}$ means of comparable sample variables, variance (standard deviation squared) of comparable samples sample sizes of comparable samples

and compared with $t$-statistics critical values $t_{v, \alpha}$, 
where degrees of freedom $(d f)$ for the $t$-test statistics are calculated as follows:

$$
d f=\frac{\left[\left(\frac{s_{i}^{2}}{n_{i}}\right)+\left(\frac{s_{j}^{2}}{n_{j}}\right)\right]^{2}}{\frac{\left(\frac{s_{i}^{2}}{n_{i}}\right)}{\left(n_{i-1}\right)}+\frac{\left(\frac{s_{i}^{2}}{n_{i}}\right)}{\left(n_{j-1}\right)}}
$$

Also, $p$-values were calculated for given test statistics and the degrees of freedom. The $p$ value is the probability of obtaining a value of the test statistic as extreme as or more extreme than the actual value obtained when the null hypothesis is true. Thus, the $p$-value is the smallest significance level at which a null hypothesis can be rejected, given the observed sample statistic. As calculated $t$-statistic $(0,16)$ is smaller than critical values $(1,96)$ for degrees of freedom (689) and $\alpha=0,05$, authors cannot reject the null hypothesis - sample data does not give sufficient evidence that mixed IMS provide higher idea quantity than external. This conclusion is supported also by $p$-value $>0,05$.

\subsection{Basic data characteristics - idea quality}

Respondents frequency distribution based on survey data is shown in Figure 2.

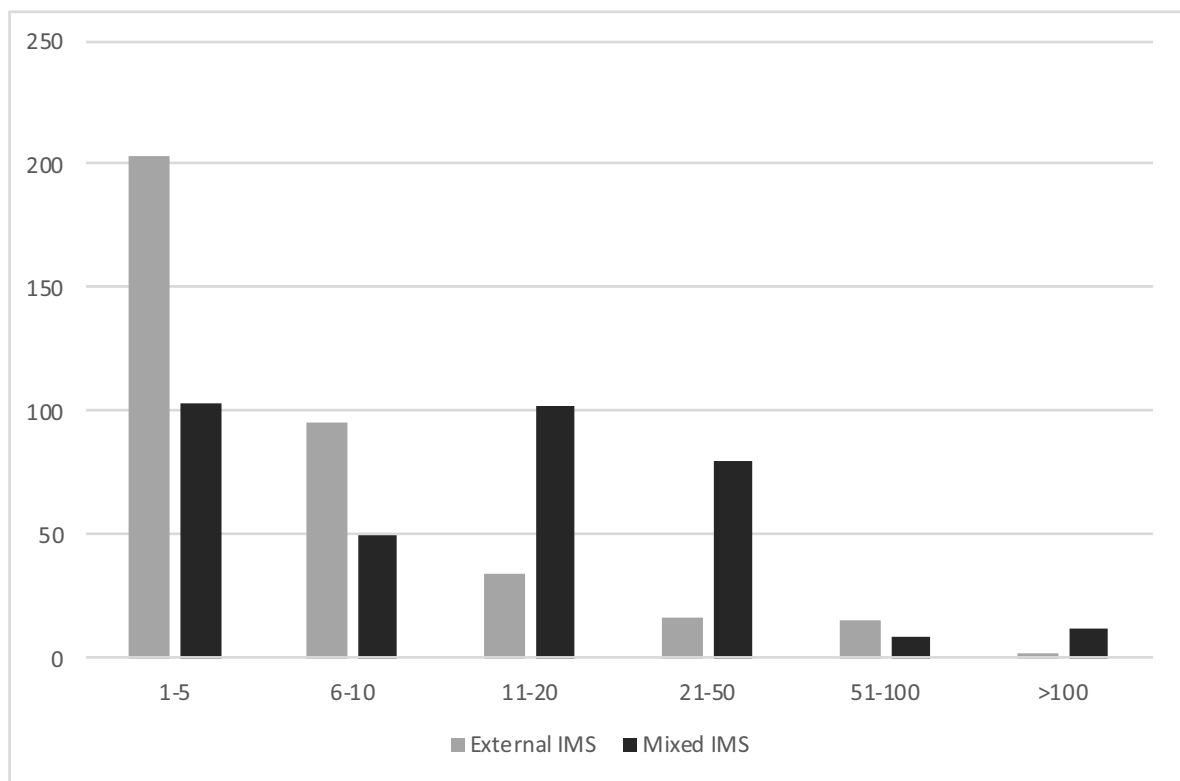

Fig. 2. Respondents frequency distribution for idea quality based on sample data Source: created by author's

Point estimates for idea quality were aggregated and are provided in Table 2.

Table 2. Point estimates for idea quality

\begin{tabular}{|c|c|c|c|c|c|}
\hline IMS type & $\boldsymbol{n}$ & Mean & Median & $\boldsymbol{s}$ & $\boldsymbol{C} \boldsymbol{V}$ \\
\hline External IMS & 367 & 10,84 & 4,62 & 18,28 & $169 \%$ \\
\hline Mixed IMS & 356 & 20,89 & 11,48 & 26,31 & $126 \%$ \\
\hline
\end{tabular}


As shown in Table 2, the medians for both IMS types are less than the means of the selected ideas. These differences indicate asymmetry in the distribution of respondents - more often a smaller number of ideas are selected, but less often - a large number of ideas. As frequency distributions are skewed mean values does not give a good idea of a typical value that can be expected in case of using these types of IMS. The calculated coefficients of variation indicate that, using external IMS, larger volatilities in the number of selected ideas must be taken into account.

\subsection{Hypothesis testing - idea quality}

A respondent's frequency distribution shows the main trend that will be tested: mixed IMS provides higher idea quality than external IMS.

Hypothesis 2 statement: Mixed IMS provide higher idea quality than external IMS

$$
H_{0}: \bar{x}_{M S}-\bar{x}_{E S} \leq 0 \text { and } H_{A}: \bar{x}_{M S}-\bar{x}_{E S}>0
$$

As calculated t-statistic $(5,95)$ is larger than critical values $(1,96)$ for degrees of freedom (631) and $\alpha=0,05$, authors would reject the null hypothesis and conclude that sample data provide strong evidence to support alternative hypothesis. Conclusion that mixed IMS provide higher idea quality is supported also by $\mathrm{p}$-value $<0,0001$.

\subsection{Basic data characteristics - involvement}

Respondents frequency distribution based on survey data is shown in Figure 3

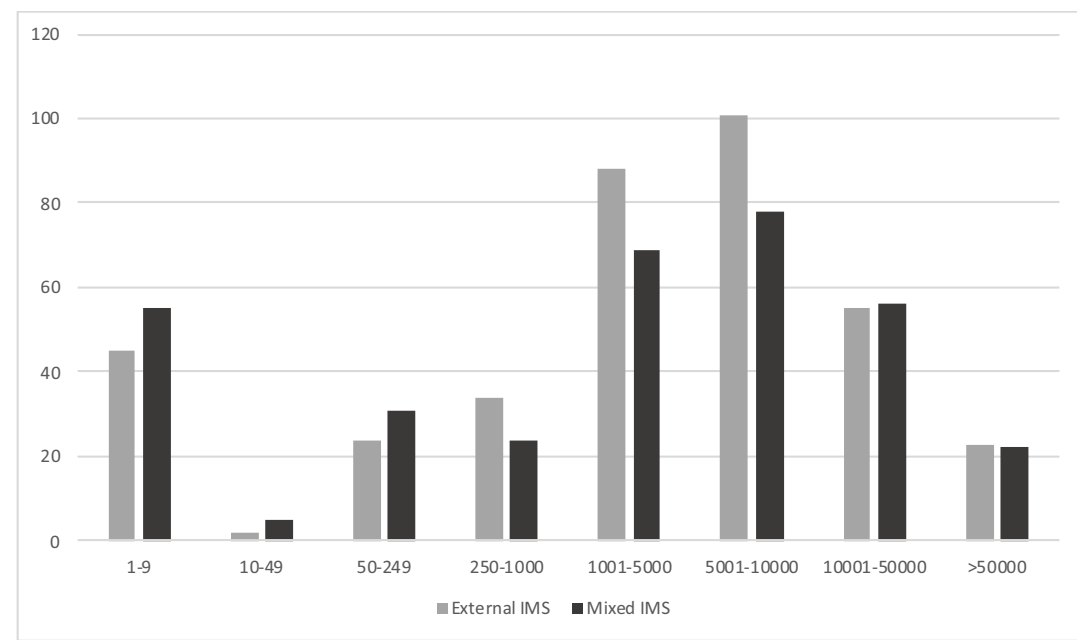

Fig. 3. Respondents frequency distribution for involvement based on sample data Source: created by author's

Point estimates for involvement were aggregated and are provided in Table 3.

Table 3. Point estimates for involvement

\begin{tabular}{|c|c|c|c|c|c|}
\hline IMS type & $\boldsymbol{n}$ & Mean & Median & $\boldsymbol{s}$ & $\boldsymbol{C V}$ \\
\hline External IMS & 372 & 11886,4 & 4682,3 & 18920,0 & $159 \%$ \\
\hline Mixed IMS & 340 & 12182,8 & 4188,9 & 19485,1 & $160 \%$ \\
\hline
\end{tabular}


As shown in Table 3, the medians for both IMS types are less than the means of the involvement. These differences indicate asymmetry in the distribution of respondents - more often a smaller involvement, but less often - a large involvement. As frequency distributions are skewed mean values does not give a good idea of a typical value that can be expected in case of using these types of IMS. The calculated coefficients of variation indicate equal volatilities in the number of involved.

\subsection{Hypothesis testing - involvement}

A respondent's frequency distribution shows the main trend that will be tested: mixed IMS requires higher involvement than external IMS. Hypothesis 3 statement: Mixed IMS requires higher involvement than external IMS.

$$
H_{0}: \bar{x}_{M I}-\bar{x}_{E I} \leq 0 \text { and } H_{A}: \bar{x}_{M I}-\bar{x}_{E I}>0
$$

As calculated $t$-statistic $(0,21)$ is smaller than critical values $(1,96)$ for degrees of freedom (700) and $\alpha=0,05$, authors cannot reject the null hypothesis - sample data does not give sufficient evidence that mixed IMS requires higher involvement than external. This conclusion is supported also by $p$-value $>0,05$.

\subsection{Hypothesis testing - open innovation stimulation}

The results of the survey, which characterize the importance of different types of IMS in promoting open innovation, are summarized in the table below. The last column of Table 4 contains the proportion $(P)$ of respondents who believe that the particular type of IMS stimulates open innovation to the total number of respondents who use this type of IMS:

$$
P_{i}=\frac{k_{i}}{n_{i}}
$$

Table 4. Survey data on open innovation stimulation density

Source: created by author's

\begin{tabular}{|l|c|c|c|}
\hline IMS type & $\boldsymbol{n}$ & $\boldsymbol{k}$ & $\boldsymbol{P}$ \\
\hline External IMS & 204 & 133 & 0,652 \\
\hline Mixed IMS & 256 & 215 & 0,840 \\
\hline Pooled & 450 & 348 & 0,757 \\
\hline
\end{tabular}

The pooled proportion is calculated as follows:

$$
P_{C}=\frac{k_{E}+k_{M}}{n_{E}+n_{M}}
$$

Hypothesis 4 statement: Open innovations are stimulated more by mixed IMS compared to external IMS:

$$
H_{0}: P_{M}-P_{E} \leq 0 \text { and } H_{A}: P_{M}-P_{E}>0
$$

As both samples are simple random and independent, and $\mathrm{k}>100 \&(\mathrm{n}-\mathrm{k})>40$, the difference of two proportions follows an approximate normal distribution and test statistic is calculated as follows:

$$
Z=\frac{P_{M}-P_{E}}{\sqrt{P_{c} \cdot\left(1-P_{c}\right) \cdot\left(\frac{1}{n_{M}}+\frac{1}{n_{E}}\right)}}
$$

As calculated $z$-statistic $(4,66)$ is larger than critical values $(1,96)$ for $\alpha=0,05$, authors would reject the null hypothesis and conclude that sample data provide strong evidence to 
support alternative hypothesis. Conclusion that mixed IMS stimulates more open innovations is supported also by p-value $<0,0001$.

\section{DISCUSION}

There is strong statistical evidence to support conclusions that: (1) mixed IMS provide higher idea quality than external; (2) mixed IMS stimulates more open innovations than external. Second conclusion is very intriguing because it shows that may by only the outsourcing, crowdsourcing is not the only way to open innovation. Maybe the mixed idea management is the future way of innovation. That means that organisations should know their internal and external idea and innovation sources and in chemistry between these elements more open innovations will be implemented. It corresponds wit newest research results such as: "that open innovation exerts positive effects on innovation radicalness depending on the breadth and depth of openness. Furthermore, network centrality plays a negative moderating role in the relationship between open innovation and innovation radicalness whereas network reach positively moderates the relationship [20]'. It proves that the centre of open innovation is not only behind the walls of organisations, but there could be several centrality points where each of them corresponds to different open innovation and idea management tasks. And Webbased IMS are systems that could provide systematic approach for that. In this process could help "a Situational Open Innovation framework that provides methodical support for companies in leveraging the complementarities between open innovation and project management towards effective partner search and selection [21]'.

\section{CONCLUSIONS}

There is strong statistical evidence to support conclusions that: (1) Mixed IMS provide higher idea quality than external; (2) Mixed IMS stimulates more open innovations than external; (3) Paper does not have sufficient evidence that mixed IMS provide higher idea quantity than external; (4) Paper does not have sufficient evidence that mixed IMS requires higher involvement than external. The application of Mixed Idea Management Systems during COVID19 time could provide more open innovations than external and that is very important conclusion. Because in this situations organisations needs to find solutions even faster that ever and mixed IMS is one of such tools.

\section{References}

1. Alonso, A.D., Kok, S.K., Bressan, A., O’Shea, M., Sakellarios, N., Koresis, A., Solis, M.B.A., Santoni, L.J.(2020). COVID-19, aftermath, impacts, and hospitality firms: An international perspective. International Journal of Hospitality Management, 91(1).

2. Chesbrough, H. (2003). Open innovation: The new imperative for creating and profiting from technology. Boston, MA: Harvard Business School Press.

3. Chesbrough, H. (2006). Open business models: how to thrive in the new innovation landscape. Boston, MA: Harvard Business School Press.

4. Dahlander, L., Gann, D.M. (2010). How open is innovation? Research Policy, 39(6), 699- 709 .

5. Gassmann, O., Enkel, E., Chesbrough, H. (2010). The future of open innovation. $R \& D$ Management, 40 (3), 213-21. 
6. West, J., Bogers. M. (2014). Leveraging external sources of innovation: A review of research on open innovation. Journal of Product Innovation Management, 31(4), 81431.

7. Chesbrough, H., Bogers, M. (2014). Clarifying an emerging paradigm for understanding innovation. Oxford: Oxford University Press.

8. Chesbrough, H., Lettl, C., Ritter, T. (2018). Value Creation and Value Capture in Open Innovation. Journal of Product Innovation Management, 35(6), 930-938.

9. Kraus, S. Clauss, T., Breier, M., Gast, J., Zardini, A., Tiberius, V. (2020). The economics of COVID-19: initial empirical evidence on how family firms in five European countries cope with the corona crisis. International Journal of Entrepreneurial Behavior \& Research, Early access.

10. Akpan, I., Soopramanien, D., Kwak, D.H. (2020). Cutting-edge technologies for small business and innovation in the era of COVID-19 global health pandemic. Journal of Small Business \& Entrepreneurship, 1-18.

11. Heinonen, K. Strandvik, T. (2020). Reframing service innovation: COVID-19 as a catalyst for imposed service innovation. Journal of Service Management, Early access.

12. Craighead, C.W., Ketcher, D.J., Darby, J.L. (2020). Pandemics and Supply Chain Management Research: Toward a Theoretical Toolbox. Decision Sciences, 51 (4), 838 866.

13. Ivanov, D. (2020). Viable supply chain model: integrating agility, resilience and sustainability perspectives- lessons from and thinking beyond the COVID-19 pandemic. Annals of Operational Research, Early access.

14. Rowan, N.J., Galanakis, C.M. (2020). Unlocking challenges and opportunities presented by COVID-19 pandemic for cross-cutting disruption in agri-food and green dealinnovations: Quo Vadis? Science of the Total Environment, 748.

15. Tanveer, M., Hassan, S., Bhaumik, A. (2020). Covid-19-quarantine-and-consumerbehavior-that-change-the-trends-of-business-sustainability-development. Academy of strategic Management, 19 (4), 1-11.

16. Caligiuri, P. De Cieri, H., Minbaeva, D., Verbeke, A., Zimmermann, A. (2020) International HRM insights for navigating the COVID-19 pandemic: Implications for future research and practice. Journal of International Business Studies, 51(5), 697-713.

17. Ferrannini, A., Barbieri, E., Biggeri, M., Di Tommaso,M.R. (2020). Industrial policy for sustainable human development in the post-Covid19 era. World Development, 137, 105215.

18. Donthu, N, Gustafsson, A. (2020). Effects of COVID-19 on business and research. Journal of Business Research, 117 (1), 284-289.

19. Moore, D., McCabe, G., Alwan, L., Craig, B. (2016). The practice of statistics for business and economics. 4th ed. New York: W. H. Freeman \& Co.

20. Lyu, Y., Zhu, Y., Han, S., He, B., Bao, L. (2020). Open innovation and innovation "Radicalness"- the moderating effect of network embeddedness. Technology in Society, 62(1), 101292.

21. Guertlerab, M.R., Sick, N. (2020). Exploring the enabling effects of project management for SMEs in adopting open innovation - A framework for partner search and selection in open innovation projects. International Journal of Project Management. 